\title{
Nanostructures and Thermal Properties of the Binary Mixture of DNA and a Zwitterionic Phospholipid in the Bulk
}

\author{
Ching-Mao Wu* and Szu-Yin Lin
}

\begin{abstract}
Material and Chemical Research Laboratories, Industrial Technology Research Institute, Chutung, Hsin-Chu, 310, Taiwan
\end{abstract}

\begin{abstract}
The mixtures of polyanionic DNA and zwitterionic phospholipids (ZL) have recently received much attention because of their potential for use as vectors in gene therapy or as a template for nanostructure construction. The past few studies on DNA-ZL system were carried out in their aqueous solutions and it was reported that a small fraction of DNA was capable of binding to zwitterionic lipids. However, it is still not known whether, as in the aqueous state, the DNA will be still intercalated between lipid bilayers in the bulk state. In the present study, we examined the DNA-ZL interactions in the bulk state by investigating a binary system composing of DNA and a zwitterionic lipid, 1,2-di(cis-9octadecenoyl)-sn-glycero-3-phosphocholine (DOPC). The nanostructures and thermotropic phase behavior of this system were investigated using small angle X-ray scattering (SAXS) and differential scanning calorimeter (DSC), respectively. Our SAXS with one-dimensional correlation function results revealed that, as in the aqueous state, the DNA/DOPC bulk mixture forms a multilamellar phase, where the DNA was confined between the DOPC lipid bilayers. The thickness of the hydrophobic layers composed of lipids tails was greater in the DNA-DOPC mixture than in the pure DOPC. However, interestingly, the thickness of the hydrophilic layer composed of lipid headgroups in the DNA-DOPC mixture was same as in the pure DOPC even though in the former DNA was intercalated in this layer. Furthermore, according to the DSC endotherms we also observe that DNA induced a significant depression of gel-to-liquid crystalline phase transition temperature of DOPC bilayer. A thermodynamic model was presented that described the experimentally observed morphological and thermotropic phase behavior.
\end{abstract}

Keywords: DNA-lipid complex, Phospholipid, Zwitterionic lipid, DNA condensation, Correlation function.

\section{INTRODUCTION}

Self-assembly of DNA-cationic liposome complexes in aqueous media has drawn significant attention largely because of their applications as nonviral vectors in gene therapy [1-5]. Recently, interests have also been directed toward the understandings of this type of complexes in the bulk state due to their potential applications as self-assembled functional materials [610]. For instance, a water-insoluble and aligned DNAcationic lipid film has been prepared as a molecular material which may exhibit one-dimensional electron transfer and conduction along the DNA strands $[6,7]$. Unlike the extensively studied bulk complexes of synthetic polyelectrolytes with oppositely charged surfactants, understanding on the structures and physicochemical properties of DNA-cationic liposome complexes in the bulk state is still limited, especially on how the structure evolves from the aqueous media to the bulk state.

Complexes formed by polyanionic DNA with cationic liposomes have been extensively explored as a promising gene delivery system in gene therapy [1, 2]. Cationic liposomes typically compose of a cationic lipid (denoted by $\mathrm{CL}$ ) and a neutral or zwitterionic lipid

\footnotetext{
*Address corresponding to this author at the Material and Chemical Research Laboratories, Industrial Technology Research Institute, Chutung, Hsin-Chu, 310, Taiwan; Tel: +886-3-5918245; Fax: +886-3-5820215;

E-mail: ChingMaoWu@itri.org.tw
}

(denoted by $\mathrm{ZL}$ ), in which the cationic lipid is mainly responsible for binding to DNA whereas the zwitterionic lipid enhances the membrane fusion between the complexes with cell membranes [1, 3-5, 11-13]. According to the pioneering studies done by Safinya et al., different zwitterionic lipids would lead to different morphologies formed by the complexes so that the extent of transfection efficiencies could differ $[4,5]$. The most well-known examples are that of DNA complexed with cationic liposomes containing DOTAP and zwitterionic DOPC which forms a multilamellar phase having alternating DNA monolayer and a lipid bilayer, where the DNA further arranges in an in-plane smectic order (denoted by $\mathrm{L}_{\alpha}{ }^{\mathrm{C}}$ phase) [4]. However, the complex formed by DNA with cationic liposomes containing DOTAP and zwitterionic DOPE adopts an inverted hexagonal phase, in which the DNA coated with a monolyaer of lipids arranges in a hexagonal order (denoted by $\mathrm{H}_{\|}{ }^{\mathrm{C}}$ phase) [5]. The transfection experiments verified that $\mathrm{H}_{\|}{ }^{\mathrm{C}}$ phase has higher transfection efficiency than $L_{\alpha}{ }^{C}$ phase [5]. Safinya's investigations also revealed that the $\mathrm{L}_{\alpha}{ }^{\mathrm{C}}-\mathrm{H}_{\|}{ }^{\mathrm{C}}$ phase transition could be mediated by changing the spontaneous curvatures of lipids and membrane rigidity [5]. Since the synthetic cationic lipids are toxic to cell, using liposomes completely composed of zwitterionic lipids (ZL) has been progressively examined as a promising alternative to cationic lipids [14-25]. Nevertheless owing to weak interactions, when DNA is added into $\mathrm{ZL}$ aqueous solution, only a small amount of 
DNA is capable of entrapped within the ZL liposomes [23-25]. Recently, to enhance the DNA-ZL interaction, divalent metal cations $\left(\mathrm{M}_{\mathrm{n}}{ }^{2+}\right)$ have been used to bridge DNA and ZLs [17-22].

Despite its promising application in medicinal field, not many studies have been carried out to explore the morphologies formed by pure binary DNA-ZL systems $[15,16,24,25]$. Malghani and Yang were the first to show using atomic force microscopy (AFM) that DNA isotropically adsorbs on the surface of the gel-state DPPC supported film in the aqueous $\mathrm{NaCl}$ solution through electrostatic attractions [24]. Pott and Roux studied DNA-DOPC system in which short DNA chains ( $\sim 150$ bp and $\sim 50 \mathrm{~nm}$ ) were mixed with shear-induced small multilamellar DOPC vesicles containing a small amount of neutral helper surfactant in water, followed by freeze-drying, and finally the mixture was dehydrated to a water content around $50 \%[15,16]$. With the aid of synchrotron small angle X-ray scattering (SAXS), the resultant mixture was examined as an ordered $\mathrm{L}_{\alpha}{ }^{\mathrm{C}}$-like multilamellar structure, in which the DNA sandwiched between the bilayers were arranged in an in-plane order [15]. They also constructed a phase diagram of the ternary DNA-DOPC-water system, which showed that the $\mathrm{L}_{\alpha}{ }^{\mathrm{C}}$-phase is the most prominent morphology in this system within certain composition ranges $[15,16]$. Furthermore, in one of our previous work, we investigated the binary DNA-DOPC systems in aqueous solution by SAXS and transmission electron microscopy (TEM). It was shown that a small fraction of DNA could bind to DOPC liposome, which subsequently induces the large-scale aggregation of the oligolamellar DOPC liposomes [25].

Since these structures were formed in the presence of excess water, the DNA phosphate groups were sufficiently hydrated such that the DNA chains in the complex adopted the common B conformation [4]. In the bulk state where most water has been removed, the secondary structure of DNA in the complex may deviate from the B conformation. Okahata et al. [6] used circular dichroism (CD) to examine the DNA conformation in the complexes with $\mathrm{N}, \mathrm{N}, \mathrm{N}$-trimethyl$\mathrm{N}$-(3,6,9,12-tetraoxadocosyl) ammonium bromide in the dry film and aqueous media. Their results revealed a BA conformational transition from wet to dry state [6]. Recently we have studied the structure of the complexes of DNA with a CL, cholesteryl $3 \beta-N-$ (dimethylamionethyl) carbamate (DC-Chol), in the hydrate and bulk state using SAXS [12, 26]. The complexes in the hydrate state were found to exhibit a multilamellar structure in which the DNA confined in the hydrophilic layers adopted B conformation. Both the interlamellar distance $(\approx 6.28 \mathrm{~nm})$ and the in-plane interhelical distance of DNA $\left(\mathrm{d}_{\mathrm{DNA}} \approx 2.5 \mathrm{~nm}\right)$ were independent of the lipid-to-base pair molar ratio $(x)$ [12]. When most water was removed, the complexes with $x$ lying above the isoelectric composition $(x>2)$ displayed a multilamellar structure (denoted by $L_{\|}$ phase) identical to that formed in the hydrate state in terms of the interlamellar distance and DNA conformation. By contrast, the complex with $x<2$ showed another multilamellar structure (denoted by $L_{1}$ phase) consisting of A-form DNA intercalated between the lipid bilayers with tilted tails [26].

In contrast to the rich DNA conformational transition of DNA-CL complexes from aqueous solution to bulk state, it is still not known whether the DNA is still intercalated between ZL bilayers in the bulk state. Once the aqueous DNA-ZL solution dries, it is quite possible for the DNA to de-mix from ZLs. However, if the de-mixing does not occur, we may expect some distinct and interesting morphologies for the bulk DNAZL system similar to that observed in case of bulk DNA-CL complexes $[10,26]$. To our knowledge, such a study of DNA-ZL bulk systems had not been reported in the past. Hence, the present work attempts to further explore DNA-DOPC system in the bulk state. The selfassembled structures and thermotropic phase behavior of this system was investigated using SAXS and differential scanning calorimeter (DSC), respectively. Our SAXS results will show that DNA was still confined between the DOPC lipid bilayers even in the bulk state. Furthermore, we also demonstrate that DNA induces a significant depression of gel-to-liquid crystalline phase transition temperature of DOPC bilayer, as observed by DSC endotherms.

\section{EXPERIMENTAL SECTION}

\section{Materials and Sample Preparations}

DNA type XIV from herring testes with the average molecular weight of ca. 700 base pairs (bp) and the ZL, 1,2-di(cis-9-octadecenoyl)-sn-glycero-3-

phosphocholine (DOPC), were acquired from Sigma and directly used without further purification. The preparation of DOPC liposomes has been described elsewhere [25]. Briefly, the prescribed amount of DOPC was first dissolved in chloroform, then directly dried under vacuum until complete removal of the solvent. Subsequently DOPC was hydrated by distilled water for 30 minutes at room temperature and then was mixed for another 10 minutes by a vortex mixer. 
Finally, the reduction of liposome size was carried out via sonication in a temperature-controlled ultrasonic bath at $40{ }^{\circ} \mathrm{C}$. The DNA/DOPC suspension was prepared by directly mixing DNA $(10 \mathrm{mg} / \mathrm{mL})$ with the DOPC suspension at desired compositions. This mixing resulted in visually observable precipitation. The overall composition of the mixture was expressed by the lipid-to-base-pair molar ratio $(\mathrm{v})$. The concentration of DNA/DOPC in water was controlled at around 5.0 wt\% (or water content $\approx 95 \%$ ). Subsequently, the mixture solution was slowly evaporated under a stream of $\mathrm{N}_{2}$ gas until dry DNA/DOPC mixture was obtained. All the test specimens were stored in a desiccator under vacuum before measurements.

\section{SAXS Measurements}

The nanostructures formed by bulk DNA/DOPC mixtures were probed with a Bruker Nanostar SAXS instrument, which consisted of a Kristalloflex K760 1.5 $\mathrm{kW}$ X-ray generator (operated at $40 \mathrm{kV}$ and $35 \mathrm{~mA}$ ) and cross-coupled Göbel mirrors for $\mathrm{Cu}$ Ka radiation $(\lambda=$ $1.54 \AA$ ) resulting in a parallel beam of about $0.05 \mathrm{~mm}^{2}$ in cross section at the sample position. This instrument also contained a sample chamber connected to a vacuum pump so that the measurements could be executed under an extremely low vacuum. The scattering intensity was detected by a Siemens multiwire type area detector with $1024 \times 1024$ resolution mode. The specimens for SAXS measurement were prepared by directly introducing the dry powder into the sample cell comprising two Kapton windows and were measured at $20{ }^{\circ} \mathrm{C}$. All the SAXS data were corrected for empty beam scattering, background and the sensitivity of each pixel of the area detector. The area scattering pattern had been circularly averaged to increase the photon counting efficiency compared with the one-dimensional linear detector. The resulting intensity profile was output as a plot of the scattering intensity $(I)$ versus the scattering vector, $q=(4 \pi / \lambda) \sin (\theta / 2)(\theta=$ scattering angle $)$.

\section{DSC Scans}

The gel-to-liquid crystalline phase transition temperature originating from the long acyl chainmelting of the DOPC lipid was measured using a TA Instrument 2000 differential scanning calorimeter (DSC) equipped with a RCS cooling system. For each scan, ca. $5 \mathrm{mg}$ of the specimen was placed in an aluminium pan which was then sealed immediately and was subsequently equilibrated for two days at room temperature before DSC scans. For DSC scans, an indium standard was first used for the calibration of heat flow and temperature. All the DSC scans, then, were carried out from $-50{ }^{\circ} \mathrm{C}$ to $40{ }^{\circ} \mathrm{C}$ at a heating rate of $2{ }^{\circ} \mathrm{C} / \mathrm{min}$ in a nitrogen atmosphere.

\section{RESULTS AND DISCUSSION}

\section{Structure in the Bulk State}

The highly-hydrated DOPC typically depicts a fluidlike $L_{\alpha}$ lamellar phase with a limiting interlamellar distance of ca. 6-7 nm at room temperature, in which an aqueous layer is sandwiched between the lipid bilayers [27, 28]. As the DOPC sample is dried, the thickness of water layer gradually reduces and on complete drying a two-phase lamellar phase is observed [28]. Such a self-assembled nanostructure could be easily probed using SAXS. Figure 1 shows a Lorentz-collected SAXS profile $\left(I(q) q^{2}\right.$ vs $\left.q\right)$ of neat DOPC in the bulk state, which was collected at room temperature. The profile displays two equally-spaced diffraction peaks located at $\mathrm{q}=1.54 \mathrm{~nm}^{-1}$ along with $\mathrm{q}=$ $3.04 \mathrm{~nm}^{-1}$, clearly indicating the formation of fluid-like $L_{\alpha}$ lamellar stacking. The interlamellar distance (d) calculated from Bragg's law $\left(d=2 \pi / q_{m}\right.$ with $q_{m}$ being the position of primary diffraction peak) was found to be ca. $4.08 \mathrm{~nm}$. The lamellar structure primarily consisted of alternating hydrophilic layer (containing bilayer of polar headgroups and absorbed water molecules) and

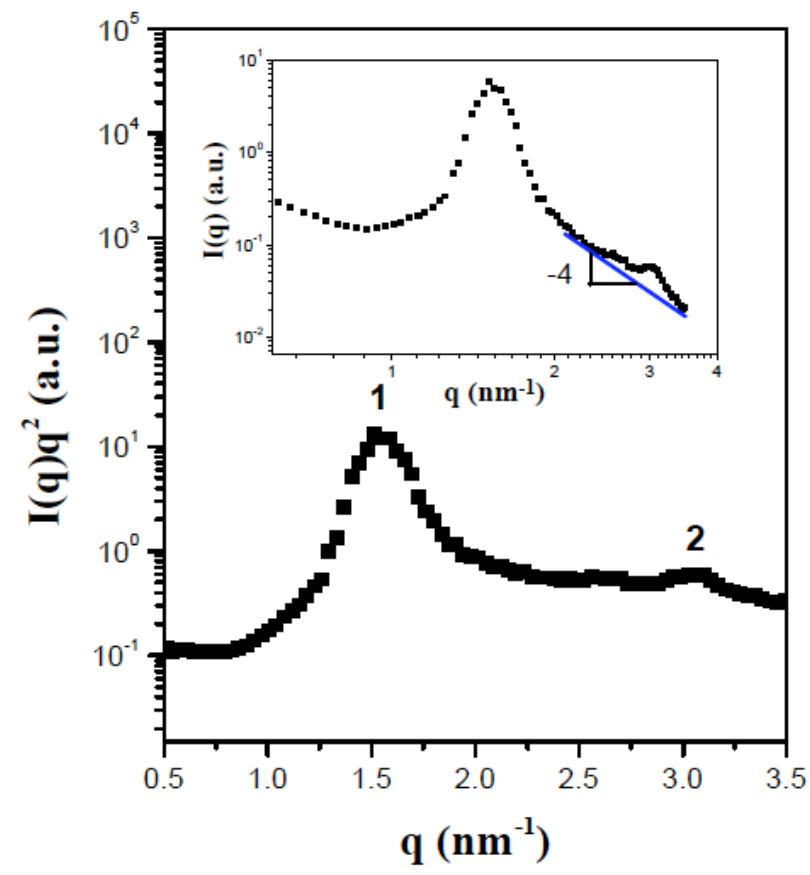

Figure 1: Lorentz-corrected SAXS profile of neat DOPC. The inset displays the scattering profile in log-log plot to demonstrate the Porod asymptotic scattering behavior, i.e. $\mathrm{I}(\mathrm{q}) \sim \mathrm{q}^{-4}$. 
hydrophobic layer (comprising bilayer of acyl tails). Furthermore, as could be observed from the inset in Figure 1 the slope of log-log plot of I(q) vs $q$ at high-q region approaches -4 , which showed that the system closely followed Porod's law $\left(\mathrm{I}(\mathrm{q}) \sim \mathrm{q}^{-4}\right.$ for large $\mathrm{q}$ region) and thus it displayed a two-phase internal structure with a sharp boundary interface [29]. Recently, Pereira-Lachataignerais et al. also observed that the internal structure of low-hydrated DOPC (under relative humidity of $1 \%$ ) displays a sinusoidal curve of the electron density profile [28]. Such a sinusoidal curve typically represents a two-phase system. The dried DOPC does not possess water gap situated between the lipid bilayers but exhibits a closer proximity between the two monolayers of lipid headgroups, leading to an average scattering density length in the hydrophilic layer.

Figure 2 shows the room-temperature SAXS profiles of the bulk DNA/DOPC mixtures as a function of the prescribed compositions. As shown in Figure 2, only two diffraction peaks were observed in the intensity profiles of all mixtures. The peak positions were found to be independent of composition. Since the peak positions observable in the scattering profiles do not exhibit any meaningful relationship in the relative positions and higher order peaks were absent, a detailed evaluation of the SAXS data was necessary for assigning the microphase-seperated structure of the mixtures. In our previous work [25], we have shown that irrespective of the composition only a small fraction of DNA was bound with the oligolamellar DOPC liposomes and this bound DNA then induces the aggregation of the DOPC liposomes in the solution. Hence, the solution of DNA/DOPC mixture was composed of free DNA and DOPC vesicles apart from the DNA-bound DOPC vesicular aggregates. Upon drying, the obtained as-casted film was then expected to have similar composition as in the aqueous state. Moreover, in this case, the lamellar morphologies observed for pure DOPC and DNA-bound DOPC in solution state was also expected to be retained in the bulk state. In Figure 2, the sharper peak located at $q=$ $1.52 \mathrm{~nm}^{-1}$ corresponded to the primary peak position of neat DOPC and was thus attributable to the $L_{\alpha}$ lamellar structure formed by DNA-free DOPC phase (i.e., pure DOPC). On the other hand, the other peak positioned at lower $\mathrm{q} \sim 1.20 \mathrm{~nm}^{-1}$ originated from the microphaseseparated structure formed by the DNA-intercalated DOPC phase (from hereon DNA/DOPC phase). In this case the incorporation of DNA into the hydrophilic layer of DOPC swells the interlamellar distance and hence

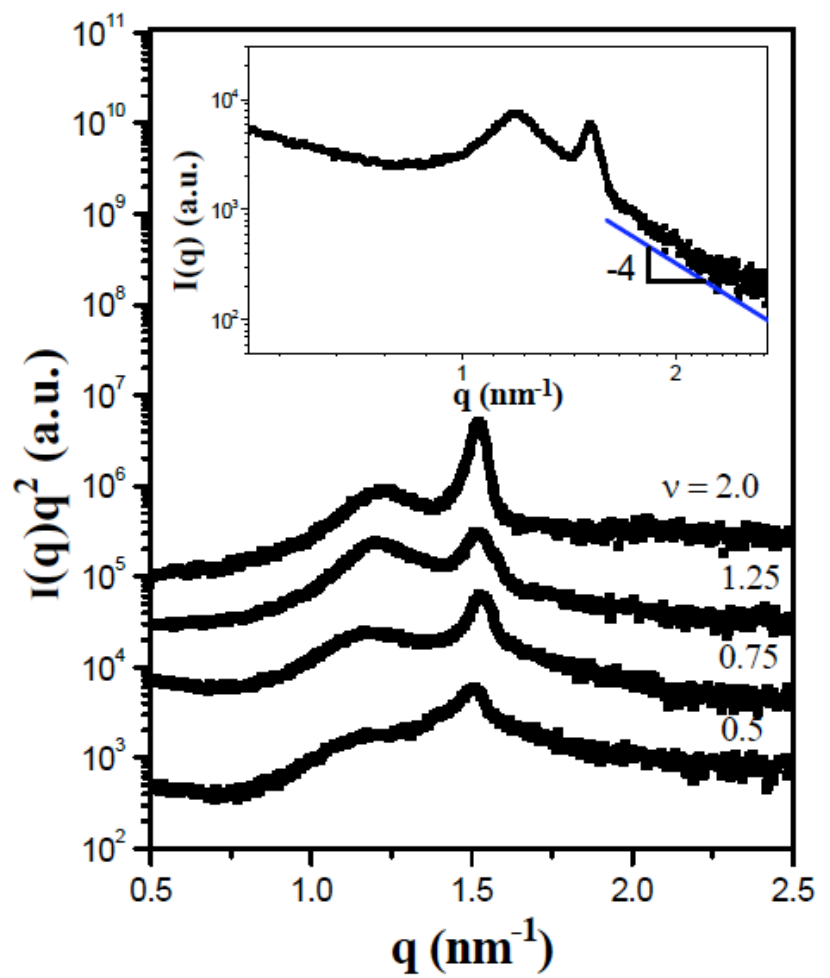

Figure 2: Representative Lorentz-corrected SAXS profiles of bulk DNA/DOPC mixture as a function of prescribed composition (v). The inset shows the scattering profile in loglog plot of $v=1.25$ to demonstrate the Porod asymptotic scattering behavior, i.e. $\mathrm{I}(\mathrm{q}) \sim \mathrm{q}^{-4}$.

the peak shifts to the lower q region compared to that due to the pure DOPC. It must be noted here that in the absence of higher order peak, the peak at $\mathrm{q} \sim 1.20 \mathrm{~nm}^{-}$ 1 may also be ascribed due to "correlation-hole" effect from concentration fluctuations in the DNA/DOPC mixture. However, such a correlation-hole effect was ruled out here considering that the peak observed in Figure 2 was sharper than the typical correlation-hole peak. Moreover, the SAXS intensity due to contribution from concentration fluctuations usually follows the wellknown Ornstein-Zernicke equation [30] which prescribes $\mathrm{a} \mathrm{q}^{-2}$ dependence for the scattered intensity in the high-q region. In the present case, however, the slope of the log-log plots of $I(q)$ vs $q$ at high $q$ is about 4 , which corresponds to the scattering from a twophase system with sharp phase boundary given by the Porod's law [31, 32]. The absence of a scattering peak characteristic of the in-plane ordering of the intercalated DNA chains suggested that these DNA chains here were loosely and isotropically dispersed on the surface of the lipid bilayers. It must be noted here that we could not observe the in-plane DNA-DNA correlation peak even by using high resolution SAXS instruments. In a previous study done by Pott et al. [15, $16]$, on the DNA-DOPC system containing a small 
amount of neutral helper surfactants in water, it was observed from the SAXS results that when a low DNA concentration was used to rehydrate dried DOPC (i.e., system had high DOPC/(base pair of DNA) molar ratio), DNA was found to be isotropically dispersed on the surface of the lipid bilayers. However, when DNA concentration was increased, a large amount of DNA intercalated between lipid bilayers. Hence, in this case, a strong DNA-DNA correlation peak was clearly observed in the SAXS profiles. Pott et al. further estimated the correlation length of the DNA molecules and deduced that these confined DNA molecules should be in an in-plane nematic-like ordering [16]. Therefore, in our case, the absence of in-plane peak of the confined DNA ordering in the SAXS profile was attributed to rather small amount of DNA intercalated between lipid bilayers.

It is worthwhile to note here that DNA intercalation resulted in the swelling of the interlamellar distance by ca. $0.8 \mathrm{~nm}$, which implied that DNA partly merges into the headgroup regions since B-form DNA has a diameter of ca. $2.0 \mathrm{~nm}$. Figure 2 also shows that the positions of the two peaks coexist in all SAXS profiles irrespective of the compositions. This demonstrated that increasing the DNA fraction does not promote the formation of pure DNA/DOPC phase. Although the real compositions of DNA/DOPC phase within the mixtures did not follow the prescribed compositions of the mixtures, for clarity, further discussion of these DNA/DOPC phases was done in terms of the prescribed compositions.

For visualizing a complete picture of the lamellar morphology formed by pure DOPC as well as DNA/DOPC phases, the thickness of the constituting layer i.e. the thickness of hydrophilic layer $\left(d_{h}\right)$ and the thickness of nonpolar layer $\left(\mathrm{d}_{\mathrm{m}}\right)$ were evaluated from the SAXS data. These morphological parameters may be determined conveniently from the one-dimensional correlation function, $\gamma_{1}(z)$, defined as [33]

$\gamma_{1}(z)=\frac{\int_{0}^{\infty} I(q) q^{2} \cos (q z) d q}{\int_{0}^{\infty} I(q) q^{2} d q}$

Since the experimentally accessible $q$ range is finite, extrapolation to both low and high $q$ is necessary for the integration in Eq. (1). In the present work, extrapolation to zero $q$ was accomplished by applying the Debye-Bueche model [34, 35], whereas PorodRuland model [36] was used for extension to large q. The SAXS data, before proceeding with the correlation function analysis, was corrected for the thermal diffuse scattering (TDS). The thermal diffuse scattering was considered as a positive deviation from the Porod law $[31,32]$ and may be associated with thermal motion, local disorder, or frozen-in fluctuations. $I_{\text {TDS }}$ can be regarded as a constant background and the total scattered intensity in the high-q region is expressed by the Porod-Ruland equation [36]

$I(q)=\frac{K_{P} \exp \left(-\sigma^{2} q^{2}\right)}{q^{4}}+I_{T D S}$

where $K_{p}$ is the Porod's constant and $\sigma$ is a parameter related to the thickness of interphase for a two-phase structure. The exponential term in Eq. (2) becomes insignificant at sufficiently high q such that a plot of $\mathrm{I}(\mathrm{q}) \mathrm{q}^{4}$ vs $\mathrm{q}^{4}$ would yield a straight line with a slope given by IDS.

For pure DOPC, the $\gamma_{1}(z)$ was directly calculated from SAXS intensity data in Figure 1 based on Eq. (1); however for the DNA/DOPC mixtures, since the experimentally measured scattering intensity had contribution from the DNA/DOPC phases as well as from the DNA-free DOPC phase, the scattering intensity contributions of the DNA/DOPC phase (IDNADOPC) was obtained by subtracting the scattering intensity of DNA-free DOPC phase (IDNA-free) from experimentally measured SAXS intensity $\left(I_{m}\right)$, i.e., $I_{D N A}$ DOPC $\sim I_{m}-I_{D N A-f r e e} . I_{D N A-f r e e}$ in this case was equal to the scattering intensity of neat DOPC multiplied by an arbitrary constant (i.e., IDNA-rree $\sim I_{\text {DOPC }} \times C$ ). Such a data treatment was displayed in Figure $\mathbf{3}$ for representatively illustrating the $I_{D N A-D O P C}$ obtained for $v=1.25$. Figure $\mathbf{4 a}, \mathbf{b}$ shows the typical one dimensional correlation function plot of pure DOPC and DNA/DOPC phase with $v=1.25$, respectively. The first maximum yields the most probable value of the interlamellar distance [33, 37]. Intersection of the baseline with the straight line extended from the self-correlation triangle yields the average thickness of the thinner layer in the lamellar stacks, which was $d_{h}$ in this case. From the $\gamma_{1}(z)$ plot of pure DOPC shown in Figure $\mathbf{4 a}, d_{h}$ was found to be $1.75 \mathrm{~nm}$ and $d_{m}\left(=d-d_{h}\right)$ was $2.33 \mathrm{~nm}$. However, for the DNA/DOPC phase with $v=1.25$ though the $d_{h}$ was around $1.69 \mathrm{~nm}$, the $\mathrm{d}_{\mathrm{m}}$ was found to be $3.57 \mathrm{~nm}$ which was significantly greater than that in case of pure DOPC. Similar values of $d_{h}$ and $d_{m}$ were obtained for DNA/DOPC phases with other compositions also (cf. Table 1).

It was surprising that even though the DNA was situated in the hydrophilic layer, it was the nonpolar 


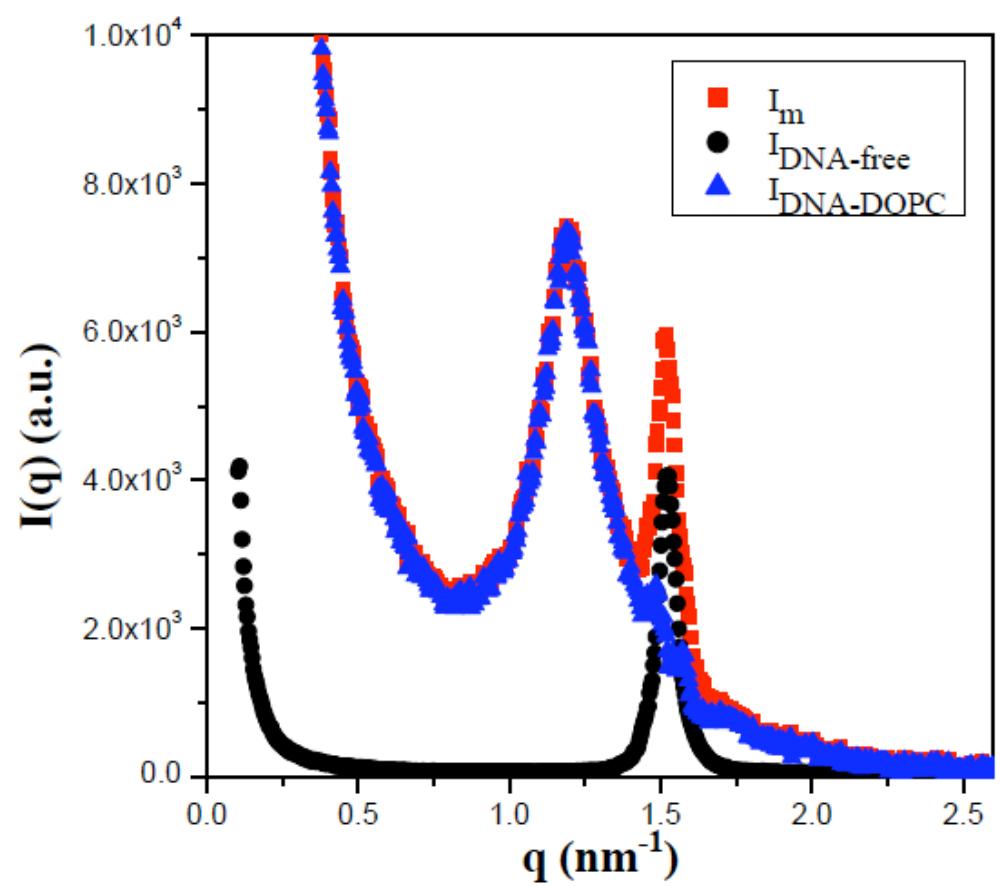

Figure 3: Representative scattering profile of DNA/DOPC mixture with $v=1.25$ for illustrating how to deduce the pure scattering contribution from the microphase-separated structure formed by DNA/DOPC phase with $v=1.25$.

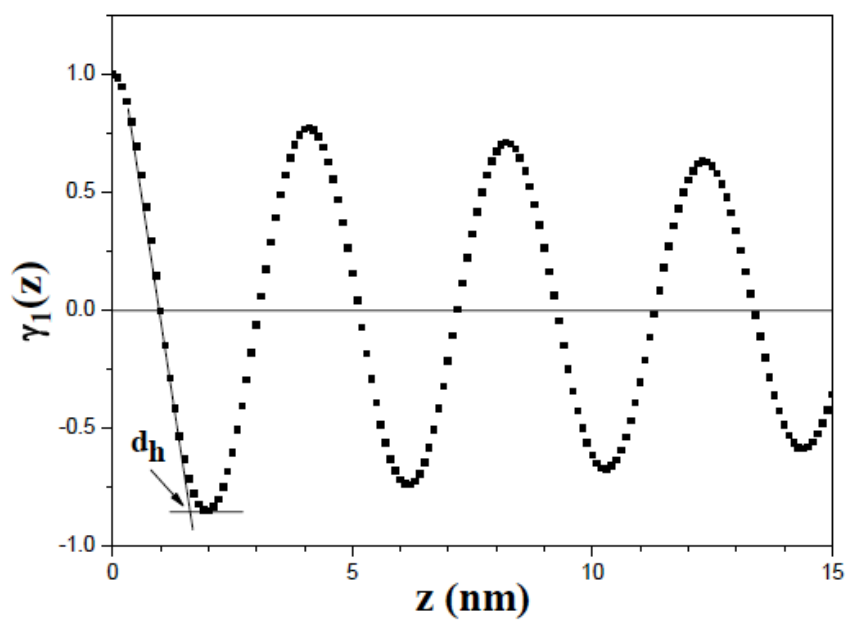

(a)

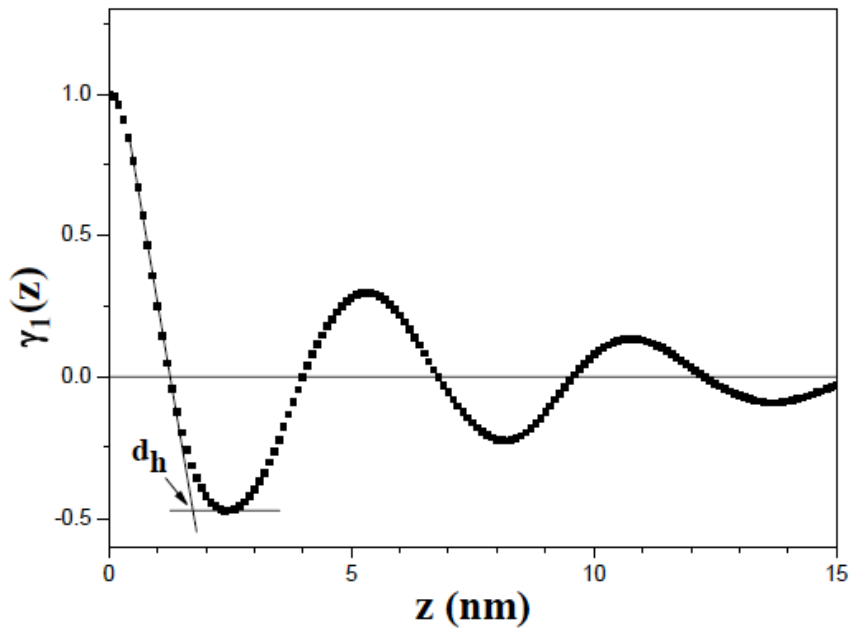

(b)

Figure 4: Representative $\gamma_{1}(\mathrm{z}) \mathrm{s}$ calculated from (a) DOPC and (b) DNA/DOPC phase with $\mathrm{v}=1.25$.

Table 1: The Structural Characteristics of DOPC and the DNA/DOPC Phases Deduced from the SAXS Intensities

\begin{tabular}{|c|c|c|c|c|c|}
\hline & $\mathbf{d}(\mathbf{n m})^{\mathbf{a}}$ & $\mathbf{d}_{\mathbf{h}}(\mathbf{n m})^{\mathbf{b}}$ & $\mathbf{d}_{\mathbf{m}}(\mathbf{n m})^{\mathbf{b}}$ & $\mathbf{I}_{\mathbf{p}}{ }^{\mathbf{c}}$ & $\mathbf{S} / \mathbf{S}_{\mathbf{0}}$ \\
\hline \hline DOPC & 4.08 & 1.75 & 2.33 & 1.81 & 1.1 \\
\hline $\mathrm{V}=2.0$ & 5.23 & 1.67 & 3.56 & 2.25 \\
\hline $\mathrm{V}=1.25$ & 5.26 & 1.69 & 3.57 & 2.23 & 1.01 \\
\hline $\mathrm{v}=0.75$ & 5.43 & 1.72 & 3.71 & 2.33 \\
\hline
\end{tabular}

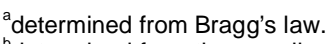

determined from the one-dimensional correlation function.

determined from the three-dimensional correlation function. 


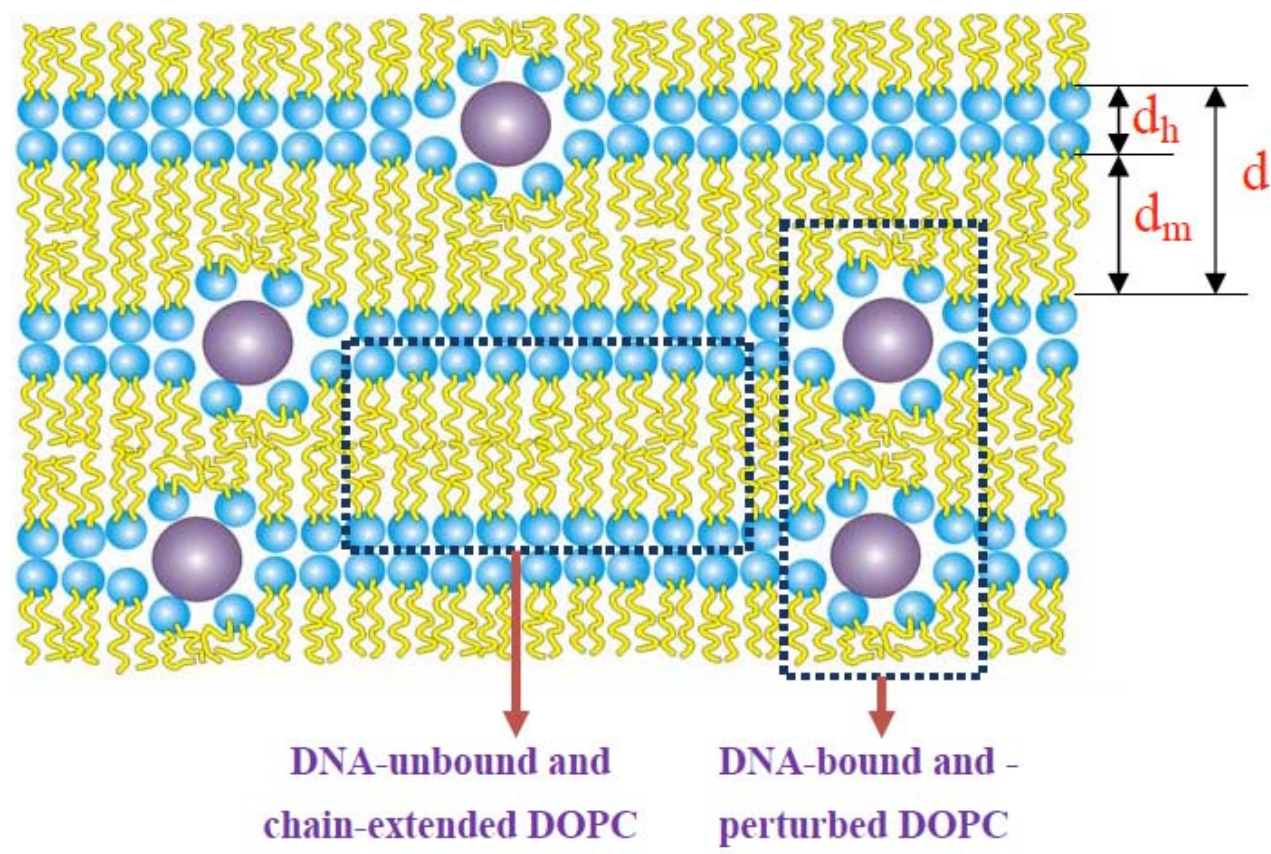

Figure 5: Schematic illustration of the microphase-separated structure formed by DNA/DOPC phase. This structure consisted of DNA-perturbed DOPC phase and pure DOPC phase with extended acyl chains.

layer thickness $\left(d_{m}\right)$ which increased significantly. This indicated that in the DNA/DOPC phase the acyl chain tails of DOPC were stretched. The increase in the nonpolar layer thickness of the DNA/DOPC phase could be understood from the schematic illustration shown in Figure 5. The figure shows the DNA-bound DOPC lipids and DNA-unbound DOPC domains arranged in a lamellar structure. DNA chains are neither homogeneously incorporated into each hydrophilic layer nor homogeneously distributed in one hydrophilic layer. As can be observed from the figure, when DNA was incorporated into the hydrophilic layer of DOPC, a vacuum gap may form between the headgroups in the hydrophilic layer. In aqueous solution, this gap was occupied by water molecules. However, once the sample is dried, these gaps must somehow be occupied by headgroups only. Since the headgroups are small and are of finite-size, the acyl chains of lipid tails will have to stretch for efficient space-filling in the hydrophilic layer as shown in Figure 5. Hence, the nonpolar layer thickness increases accordingly which further increases the interlamellar distance.

In addition to the lamellar thickness, the average planarity of the interface between the hydrophilic polar and hydrophobic non-polar layers is an important characteristic of the morphology. For a planar interface the total interfacial area per unit volume is given by $\mathrm{S}_{0} / \mathrm{V}=2 / \mathrm{d}$. If the interface is not planar, the total $\mathrm{S} / \mathrm{V}$ would be larger than $2 / d$ [38-40]. A measure of the planarity of the interface is hence given by the ratio
$\frac{S}{S_{0}}=\frac{2 d_{h} d_{m}}{d l_{p}}$

Here $I_{p}$ is the porod length which is defined as a three dimensional averaged length between the phase boundary of a two-phase system. The porod length can be calculated using the three-dimensional correlation function defined as

$\gamma_{3}(r)=\frac{\int_{0}^{\infty} I(q) q^{2} \sin (q r) / q r d q}{\int_{0}^{\infty} I(q) q^{2} d q}$

The Porod's law at large q prescribes $\gamma_{3}(r)$ to adopt the following form at small radial distance

$\gamma_{3}(r)=1-\frac{1}{l_{P}}$

According to Eq. (5) $I_{p}$ can be determined from the slope of $\gamma_{3}(r)$ plot at small $r$, as demonstrated in Figure $6 \mathbf{a}, \mathbf{b}$ for pure DOPC and the DNA/DOPC phase with $\mathrm{v}$ $=1.25$, respectively. Normally, $S / S_{0}$ is equal to 1 for a planar interface, but an unplanar or undulated interface usually adopts a value $>1$. The values of $S / S_{0}$ obtained for DOPC and DNA/DOPC phases are shown in Table 1. The proximity of the calculated radius to 1.0 irrespective of the composition attests that the lamellar interfaces in the pure DOPC as well as in the DNA/DOPC phases are planar. 


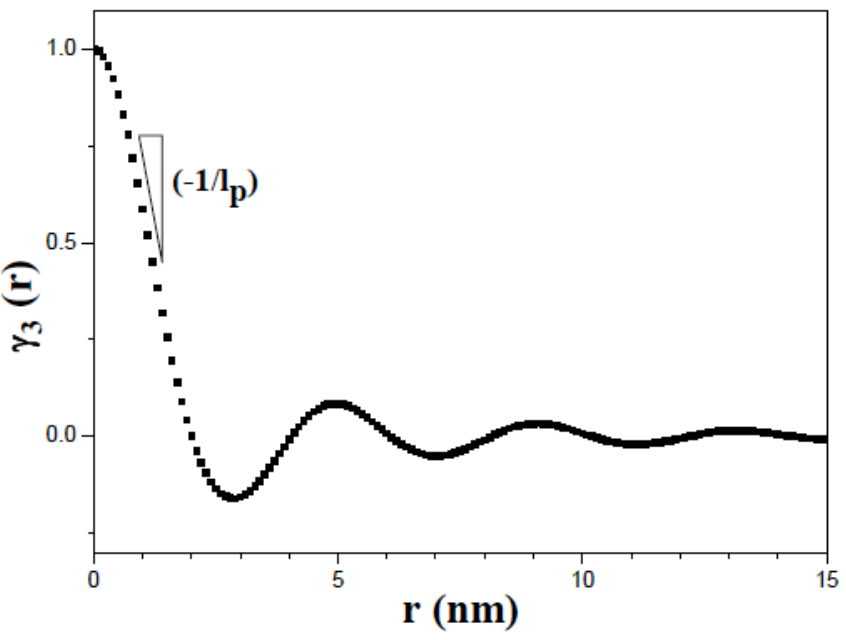

(a)

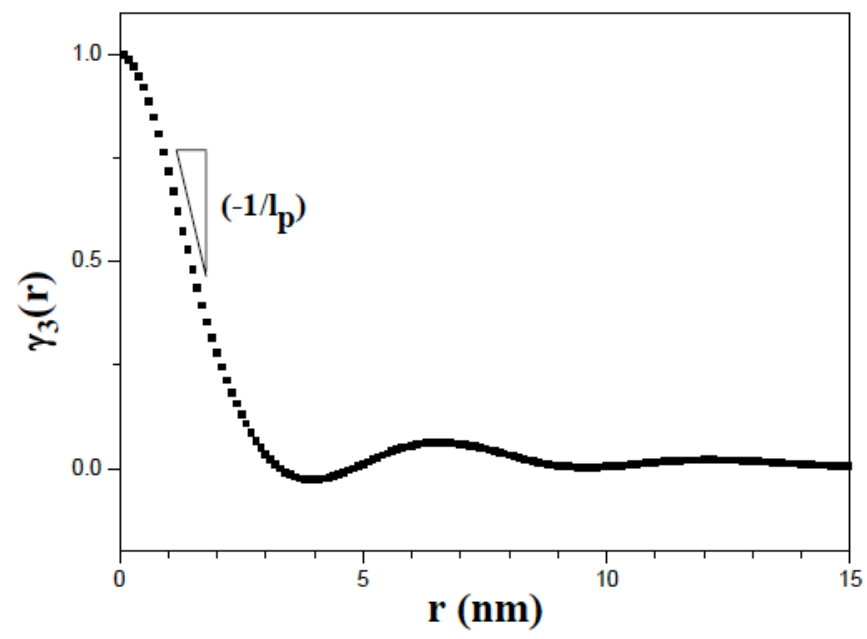

(b)

Figure 6: Representative $\gamma_{3}(z) s$ calculated from (a) DOPC and (b) DNA/DOPC phase with $v=1.25$.

\section{Thermal Properties}

Figure 7 shows the DSC endotherms of pure DOPC and DNA/DOPC mixtures in the bulk state. The pure DOPC exhibited a single endothermic peak positioned at $-2.5{ }^{\circ} \mathrm{C}$, which represented the gel-to-liquid crystalline phase transition temperature $\left(\mathrm{T}_{\mathrm{m}}\right)$ resulting from the melting of acyl chain of the lipid tails. For DOPC lipid bilayer, the $T_{m}$ here actually signified the transition from sub-gel state (i.e., $L_{C}$ phase) to liquidcrystalline or fluid state (termed as $L_{\alpha}$ phase). The gel state here was defined as the highly ordered $L_{C}$ phase [41, 42]. According to Ulrich et al. [42], the vacuumdried DOPC also contained at least one water molecule per lipid, which was tightly bound to the phosphate group on the lipid headgroup and hence was difficult to be removed completely. Ulrich et al. performed a series of DOPC hydration experiments via DSC and demonstrated that an increase in hydration gradually led to the decrease of the acyl chain-melting transition and finally reached its limiting temperature and hydration at $16.5^{\circ} \mathrm{C}$ with 9 water molecules per lipid ( 17 wt\%) [42]. Therefore, on the basis of the position and shape of endothermic peaks measured at various hydration studied by Ulrich et al., we could conveniently estimate the content of water in our dried DOPC sample. The results indicated that the dried DOPC sample has about 2.5 water molecules per lipid or about $5 \mathrm{wt} \%$ of the total DOPC mass was composed of water molecule.

It is noted from Figure 7 that the endotherms of all the mixtures except that for $\mathrm{v}=2.0$ display a single endothermic peak close to $-14{ }^{\circ} \mathrm{C}$ much lower than the one of pure DOPC irrespective of the prescribed compositions. Only one endothermic peak in the DSC heating scans of almost all mixtures observed here indicated that the DNA/DOPC phases might be homogeneously mixed with DNA-free DOPC phases. The significantly lower $T_{m}$ observed for the DOPC-DNA mixture could be reasonably attributed to structural defects which resulted in the reduction of overall crystallinity. As discussed above and shown in Figure $\mathbf{5}$ the DNA/DOPC phase basically was composed of chain-extended DOPC domains and DNA-perturbed

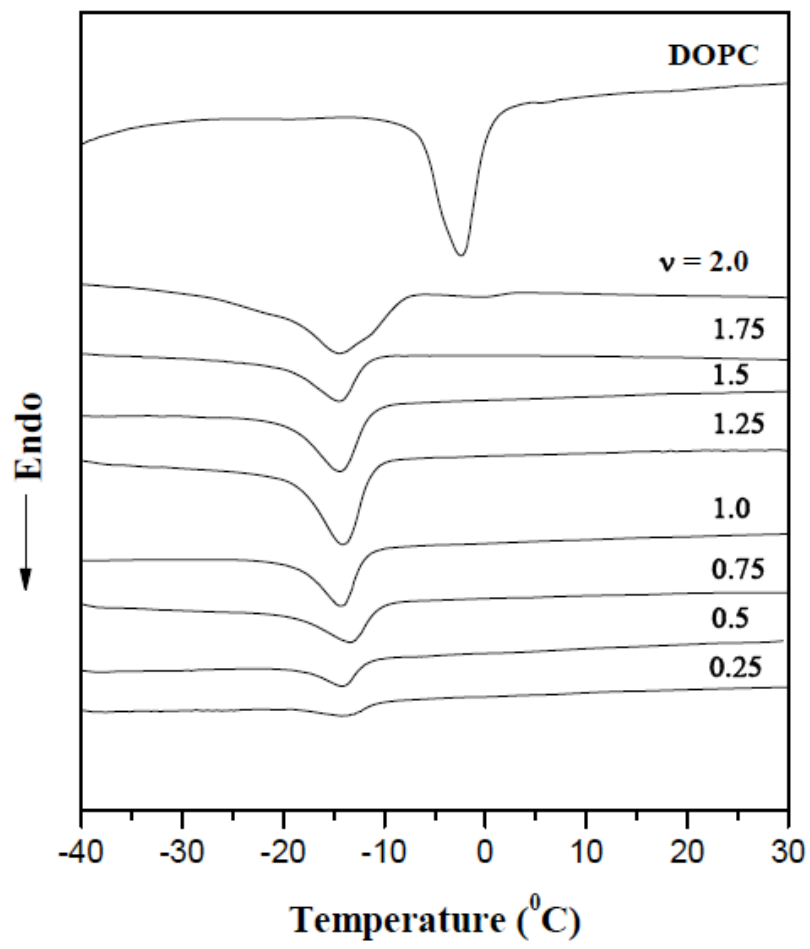

Figure 7: DSC heating thermograms of DOPC and DNA/DOPC mixtures as a function of prescribed compositions. 
DOPC molecules. The DNA-perturbed DOPC molecules bridged the two nearest neighbouring chainextended DOPC domains. Thus when the temperature was lowered to the gel state, the pure DOPC lipids and chain-extended DOPC lipids self-organized into ordered $L_{C}$ phase, however, the DNA-perturbed DOPC molecules embedded between these ordered DOPC domains played a role of impurity, resulting in structural defects coexisted with the crystallized DOPC domains. This led to a decrease in the overall crystallinity and intuitively lowered the $T_{m}$ also. There is also a possibility that the depression in $\mathrm{T}_{\mathrm{m}}$ in the DOPC-DNA mixture may in part be also due to the fact that hydrophilic DNA usually carries a large amount of water molecules for the sake of maintaining B-form conformation. A small fraction of these water molecules might also be absorbed by the lipid headgroups leading to the depression in $T_{m}$.

As noted above, the DSC thermogram of DNA/DOPC mixture with $\mathrm{v}=2.0$ showed multiple endotherms. The multiple endotherms observed in this case may be due to the presence of excess of DOPC. The excess DOPC would result in macrophase separation so that the mixture was expected to contain pure DOPC and DNA/DOPC phases with different fraction of DNA.

\section{CONCLUSIONS}

The nanostructures and thermal properties of pure DOPC and the mixture of DNA and zwitterionic DOPC in the bulk state were investigated using SAXS and DSC. SAXS profiles revealed that the bulk DOPC exhibited a fluid $L_{\alpha}$ phase having multilamellar stacking with a sharp and planar interface between hydrophilic layer and hydrophobic layer. The DNA/DOPC mixtures were consisted of free DNA, DNA-free DOPC phase, and the DNA/DOPC phase. The DNA/DOPC phase was also found to form a multilamellar phase with DNA loosely and heterogeneously intercalated between the lipid bilayers. Furthermore, on the basis of 1-D and 3-D correlation function analysis, the DNA/DOPC phase was found to be comprised the chain-extended DOPC domains having stretched acyl chains along with DNAperturbed DOPC domains in which the acyl chains are in the relaxed state. The DSC results demonstrated that the gel-to-liquid crystalline phase transition temperature in DOPC-DNA mixtures were significantly lower as compared to that in the pure DOPC. This depression in the phase transition temperature was qualitatively explained in terms of structural disorder and defect in the DNA/DOPC phase where the DNA- perturbed DOPC lipid embedded between the crystallized DOPC domains acted as impurities.

\section{ACKNOWLEDGEMENT}

We gratefully acknowledge financial support from Industrial Technology Research Institute, Taiwan.

\section{REFERENCES}

[1] Felgner PL, Gadek TR, Holm M, Roman R, Chan HW, Wenz $\mathrm{M}$ et al. Lipofection: A highly efficient, lipid-mediated DNAtransfection procedure. Proc Natl Acad Sci USA 1987; 84 7413-7. http://dx.doi.org/10.1073/pnas.84.21.7413

[2] Miller AD. Cationic liposomes for gene therapy. Angew Chem Int Ed 1998; 37: 1768-85.

http://dx.doi.org/10.1002/(SICI)1521 3773(19980803)37:13/14<1768::AID-ANIE1768>3.0.CO;2-4

[3] Lasic DD, Strey H, Stuart MCA, Podgornik R, Frederik PM. The structure of DNA-liposome complexes. J Am Chem Soc 1997; 119: 832-3

http://dx.doi.org/10.1021/ja962713g

[4] Rädler JO, Koltover I, Salditt T, Safinya CR. Structure of DNA-cationic liposome complexes: DNA intercalation in multilamellar membranes in distinct interhelical packing regimes. Science 1997; 275: 810-4.

http://dx.doi.org/10.1126/science.275.5301.810

[5] Koltover I, Salditt T, Rädler JO, Safinya CR. An inverted hexagonal phase of cationic liposome-DNA complexes related to DNA release and delivery. Science 1998; 281: 7881.

http://dx.doi.org/10.1126/science.281.5373.78

[6] Tanaka K, Okahata Y. A DNA-lipid complex in organic media and formation of an aligned cast film. J Am Chem Soc 1996; 118: 10679-3.

http://dx.doi.org/10.1021/ja9617855

[7] Okahata Y, Kobayashi T, Tanaka K, Shimomura M. Anisotropic electric conductivity in an aligned DNA cast film. J Am Chem Soc 1998; 120: 6165-6. http://dx.doi.org/10.1021/ja980165w

[8] Ikkala O, ten Brinke G. Functional materials based on selfassembly of polymeric supramolecules. Science 2002; 295 2407-9.

http://dx.doi.org/10.1126/science. 1067794

[9] Fukushima T, Hayakawa T, Inoue Y, Miyazaki K, Okahata Y. Intercalation behavior and tensile strength of DNA-lipid films for the dental application. Biomaterials 2004; 25: 5491-7. http://dx.doi.org/10.1016/j.biomaterials.2004.01.006

[10] Cui L, Miao J, Zhu L. Spacer length controlled obliquecolumnar to lamello-columnar mesophase transition in liquid crystalline DNA-discotic cationic lipid complexes. Macromolecules 2006; 39: 2536-45.

http://dx.doi.org/10.1021/ma060001x

[11] Chesnoy $S$, Huang L. Structure and function of lipid-DNA complexes for gene delivery. Annu Rev Biophs Biomol Struct 2000; 29: 27-47.

http://dx.doi.org/10.1146/annurev.biophys.29.1.27

[12] Wu CM, Liou W, Chen HL, Lin TL, Jeng US. Self-assembled structure of the binary complex of DNA with cationic lipid. Macromolecules 2004; 37: 4974-80. http://dx.doi.org/10.1021/ma049541p

[13] Wu CM, Chen CY, Lin SY, Chen HL. Effect of divalent cations on DNA condensed on the surface of rigid cationic membrane. React Funct Polym 2011; 71: 266-71.

http://dx.doi.org/10.1016/j.reactfunctpolym.2010.09.009 
[14] Tarahovsky YS, Khusainova RS, Gorelov AV, Nicolaeva TI, Deev AA, Dawson AK et al. DNA initiates polymorphic structural transition in lecithin. FEBS Lett 1996; 390: 133-6. http://dx.doi.org/10.1016/0014-5793(96)00643-6

[15] Pott T, Roux D. DNA intercalation in neutral multilamellar membranes. FEBS Lett 2002; 511: 150-4. http://dx.doi.org/10.1016/S0014-5793(01)03315-4

[16] Pott T, Colin A, Navailles L, Roux D. DNA intercalation in neutral multilamellar membranes: Experiments and theory. Interface Sci 2003; 11: 249-57.

http://dx.doi.org/10.1023/A:1022139115433

[17] Francescangeli $O$, Stanic V, Gobbi L, Bruni P, lacussi M, Tosi $G$ et al. Structure of self-assembled liposome-DNAmetal complexes. Phys Rev E 2003; 67: 011904. http://dx.doi.org/10.1103/PhysRevE.67.011904

[18] McManus JJ, Rädler JO, Dawson KA. Does calcium turn a zwitterionic lipid cationic. J Phys Chem B 2003; 107: 986975. http://dx.doi.org/10.1021/jp034463d

[19] McManus JJ, Rädler JO, Dawson KAJ. Phase behavior of DPPC in a DNA-calcium-zwitterionic lipid complex studied by small-angle X-ray scattering. Langmuir 2003; 19: 9630-7. http://dx.doi.org/10.1021/la034878q

[20] McManus JJ, Rädler JO, Dawson KAJ. Observation of a rectangular columnar phase in a DNA-calcium-zwitterionic lipid complex. J Am Chem Soc 2004; 126: 15966-7. http://dx.doi.org/10.1021/ja046105+

[21] Uhríková D, Hanulová M, Funari SS, Khusainova RS, Šeršeň F, Balgavý P. The structure of DNA-DOPC aggregates formed in presence of calcium and magnesium ions: A smallangle synchrotron X-ray diffraction study. Biochim Biophys Acta 2005; 1713: 15-28. http://dx.doi.org/10.1016/j.bbamem.2005.05.006

[22] Gromelski S, Brezesinski G. DNA condensation and interaction with zwitterionic phospholipids mediated by divalent cations. Langmuir 2006; 22: 6293-301.

http://dx.doi.org/10.1021/la0531796

[23] Monnard P, Berclaz N, Conde-Frieboes K, Oberholzer T. Decreased solute entrapment in 1-palmitoyl-2-oleoyl-snglycero-3-phosphocholine liposomes prepared by freeze/thaw in the presence of physiological amounts of monovalent salts. Langmuir 1999; 15: 7504-9. http://dx.doi.org/10.1021/la990068w

[24] Malghani MS, Yang J. Stable binding of DNA to zwitterionic lipid bilayers in aqueous solutions. J Phys Chem B 1998; 102: 8930-33.

http://dx.doi.org/10.1021/jp982413g

[25] Wu CM, Chen HL, Liou W, Lin TL, Jeng US. DNA-induced aggregation of zwitterionic oligolamellar liposome. Biomacromolecules 2004; 5: 2324-28.

http://dx.doi.org/10.1021/bm0495396

[26] Wu CM, Chen HL, Lin TL, Liou W, Lin JS. A two-state model for the multilamellar structure of a DNA/cationic lipid complex in the bulk. Langmuir 2004; 20 : 9432-6. http://dx.doi.org/10.1021/la0488856

[27] Nagle JF, Tristram-Nagle S. Structure of lipid bilayers. Biochim Biophys Acta 2000; 1469: 159-95. http://dx.doi.org/10.1016/S0304-4157(00)00016-2
[28] Pereira-Lachataignerais J, Pons R, Amenitsch H, Rappolt M, Sartori B, López O. Effect of sodium dodecyl sulfate at different hydration conditions on dioleoyl phosphatidylcholine bilayers studied by grazing incidence X-ray diffraction. Langmuir 2006; 22: 5256-60. http://dx.doi.org/10.1021/la053207k

[29] Roe RJ. Methods of X-ray and Neutron Scattering in Polymer Science. New York: Oxford University Press 2004.

[30] Ornstein LS, Zernike F. Accidental deviations of density and opalescence at the critical point of a single substance. Proc Acad Sci Amsterdam 1914; 17: 793-806.

[31] Porod G. Die Röntgenkleinwinkelstreuung von dichtgepackten kolloiden systemen. Kolloid-Z 1951; 124: 83114. http://dx.doi.org/10.1007/BF01512792

[32] Porod G. Die Röntgenkleinwinkelstreuung von dichtgepackten kolloiden systemen. Kolloid-Z 1952; 125: 51122. http://dx.doi.org/10.1007/BF01519615

[33] Strobl GR, Schneider M. Direct evaluation of the electron density correlation function of partially crystalline polymers. $J$ Polym Sci Polym Phys Ed 1980; 18: 1343.

http://dx.doi.org/10.1002/pol.1980.180180614

[34] Debye P, Bueche AM. Scattering by an inhomogeneous solid. J Appl Phys 1949; 20: 518.

http://dx.doi.org/10.1063/1.1698419

[35] Debye P, Anderson J HR, Brumberger H. Scattering by an inhomogeneous solid. II. The correlation function and its application. J Appl Phys 1957; 28: 679-83.

http://dx.doi.org/10.1063/1.1722830

[36] Ruland W. Small-angle scattering of two-phase systems: determination and significance of systematic deviations from Porod's law. J Appl Cryst 1971; 4: 70-3. http://dx.doi.org/10.1107/S0021889871006265

[37] Vonk CG. The small-angle scattering of distorted lamellar structures. J Appl Cryst 1978; 11: 541-6. http://dx.doi.org/10.1107/S0021889878013837

[38] Thünemann AF, Lochhass KH. Self-assembly of solid polyelectrolyte-silicon-surfactant complexes. Langmuir 1998; 14: 6220-25.

http://dx.doi.org/10.1021/la980229g

[39] Thünemann AF, Schnöller U, Nuyken O, Voit B. Selfassembled complexes of diazosulfonate polymers with low surface energies. Macromolecules 1999; 32: 7414. http://dx.doi.org/10.1021/ma990868d

[40] Nandan B, Chen HL, Liao CS, Chen SA. Self-assembly and crystallization in a supramolecular hairy rod polymer from the complex of polyaniline with $\omega$-methoxy poly(ethylene oxide) phosphates. Macromolecules 2004; 37: 9561-70. http://dx.doi.org/10.1021/ma048384r

[41] Koynova R, Caffrey M. Phases and phase transitions of the phosphatidylcholines. Biochim Biophys Acta 1998; 1376: 91145.

http://dx.doi.org/10.1016/S0304-4157(98)00006-9

[42] Ultrich AS, Sami M, Watts A. Hydration of DOPC bilayers by differential scanning calorimetry. Biochim Biophys Acta 1994; 1191: 225-30.

http://dx.doi.org/10.1016/0005-2736(94)90253-4 